\title{
Exploring the social and neighbourhood predictors of diabetes: a comparison between Toronto and Chicago
}

\author{
Patrycja Kolpak and Lu Wang \\ Ryerson University, Toronto, ON, Canada
}

\begin{abstract}
Objectives: This report examined the impact and extent that spatial access to primary care physicians (PCPs) and social neighbourhood-/community-level factors have on diabetes prevalence for Toronto and Chicago. Methods: The two-step floating catchment area method was used to compute spatial access scores. Bivariate correlation and multivariate linear regression identified the factors that were associated with, and/or predicted, diabetes prevalence. Results: Potential spatial access to PCPs had no strong associations with diabetes prevalence. Low socio-economic status factors and certain ethnic groups were strongly associated with diabetes prevalence for both cities. For Toronto, South American place of birth, households below poverty and high school-level education predicted diabetes prevalence. African ethnicity and households below poverty predicted diabetes prevalence for Chicago. Conclusion: Although this report found no strong association between diabetes prevalence and access to PCPs, contextual factors significant in past individual-level diabetes studies were associated with diabetes prevalence at the neighbourhood/community level for Toronto and Chicago.
\end{abstract}

Key words: community-level factors; diabetes prevalence; spatial access

Received 11 March 2016; revised 4 November 2016; accepted 18 January 2017;

first published online 8 March 2017

\section{Introduction}

Diabetes is one of the leading causes of death in many middle-high income countries; the United States has among the highest diabetic populations with 29.1 million $(9.3 \%)$ in 2014 (Centers for Disease Control and Prevention, 2014), compared with 2.4 million diabetics $(6.8 \%)$ in Canada in 2008 (Public Health Agency of Canada, 2011). Diabetes may lead to hyperglycaemia, the deterioration of blood vessel nerves and organs, and increasing morbidity and mortality rates for the population. Common risk factors include: physical inactivity, obesity, hypertension and family history of diabetes (Forouhi and Wareham, 2010). Diabetes risk prevention awareness and campaigns can

Correspondence to: Patrycja Kolpak, MSA, Ryerson University, 350 Victoria Street, Toronto, ON Canada M5B 2K3. Email: patrycja.kolpak@ryerson.ca potentially counteract diabetes development and subsequent chronic conditions.

Recent studies investigated impacts of contextual (neighbourhood)-level factors on public health. The social determinants of health framework emphasizes that socio-demographic conditions individuals collectively experience are key determinants of health (Diez Roux and Mair, 2010). Place is central as the health-related resources available and residential/neighbourhood characteristics contribute to healthy or unhealthy lifestyles (Diez Roux and Mair, 2010). Various spatial accessibility measures were developed to model the relative ease that populations are able to reach healthcare resources across areas. Generally, urban centres and certain inner city neighbourhoods were found to have greater accessibility compared with their rural and suburban counterparts (Wang and $\mathrm{Hu}, 2013$ ).

Despite the extensive literature on diabetes, there are few studies that examine how potential 
spatial access to physicians and contextual factors influence population health at the neighbourhood level (Diez Roux and Mair, 2010; GrigsbyToussaint et al., 2010; Harrington et al., 2012). This study aims to fill this gap by measuring the impact and extent that spatial (access to physicians) and contextual (neighbourhood/community level) factors have on diabetes prevalence in Toronto and Chicago. The contextual-level data come from the Canadian 2006 Census and American Community Survey (ACS) 2008-12. The two-step floating catchment area (2SFCA) method was used to compute potential spatial access measures to primary care physicians (PCPs). Bivariate correlation and multivariate linear regression models identified the important contextual factors that were associated with diabetes prevalence within Toronto neighbourhoods and Chicago communities. This study sheds light on the effect and influence that spatial and contextual factors have on neighbourhood health for two cities under different healthcare systems. It also aims to demonstrate that spatial and statistical analyses at the neighbourhood level can help identify vulnerable neighbourhoods based on relevant contextual factors.

\section{Methods}

\section{Study areas}

Toronto and Chicago have comparable population densities, are both culturally diverse and have established neighbourhoods/communities, but are under contrasting healthcare systems. Toronto, located in Southern Ontario, has 140 officially recognized neighbourhoods from six municipalities; located in Cook County, Illinois, Chicago has 77 established communities from nine 'Sides'. In 2006, Toronto housed 2503280 people, where $59.1 \%$ were first generation immigrants. Chicago had 2695598 residents in 2010; 21.2\% were foreign born and $35.8 \%$ spoke a language other than English. There were areas in both cities where low-income households spatially coincided with high diabetes prevalence, especially the U-shaped corridor in Toronto and the South Side of Chicago. Figure 1 shows the distribution of median family income and diabetes prevalence for both cities (Statistics Canada, Census 2006; US Census Bureau, 2008-12).
Canada is known for its universal healthcare system where all citizens and permanent residents, regardless of their medical history, personal income or standard of living, are covered for medically necessary preventative care and treatments. Healthcare is funded and administered by the provinces and territories. The US has a privatized healthcare system where individuals must purchase healthcare services from healthcare providers. Federal and state governments provide public coverage (Medicare and Medicaid) for eligible populations; private insurance can be acquired separately or through employment. Before Obamacare launched in 2010, nearly 47 million people were uninsured; they had limited or no access to essential healthcare services, leading to poor health outcomes (Smith, 2008).

\section{Data}

To analyse how PCPs are accessible to residents in neighbourhoods, physician data sets were acquired. The 2010 Canadian Medical Directory, acquired from Scott's Directories, contained detailed location information of all PCPs in Canada at the postal code level. The American Official Physician Compare Data was retrieved from Centers for Medicare and Medicaid Services website on 17 April 2014. Both data sets were geocoded to visualize the location of PCPs, 2859 in Toronto and 1132 in Chicago. The Chicago physician data set only included physicians enroled in Medicare; consequently, there were about 800 PCPs excluded from the data set (American Academy of Family Physicians, 2014). Generally, Medicare provides coverage for those aged 65 and over, disabled and/or diagnosed with certain critical conditions (Klees et al., 2011). This subset of physicians represent those most likely sought by vulnerable populations, and is the only publicly available physician data set for Chicago.

Diabetes prevalence data for Toronto neighbourhoods was acquired from Toronto Community Health Profiles Partnership. It consisted of age-adjusted rates of physician-diagnosed cases from registries maintained by the Institute for Clinical Evaluative Sciences. Individuals were considered diabetic if they had two physician claims, or an Ontario Health Insurance Plan claim, or a hospital admission within two years. Diabetes data for Chicago communities was obtained from the city of Chicago Health Department. 
(a)

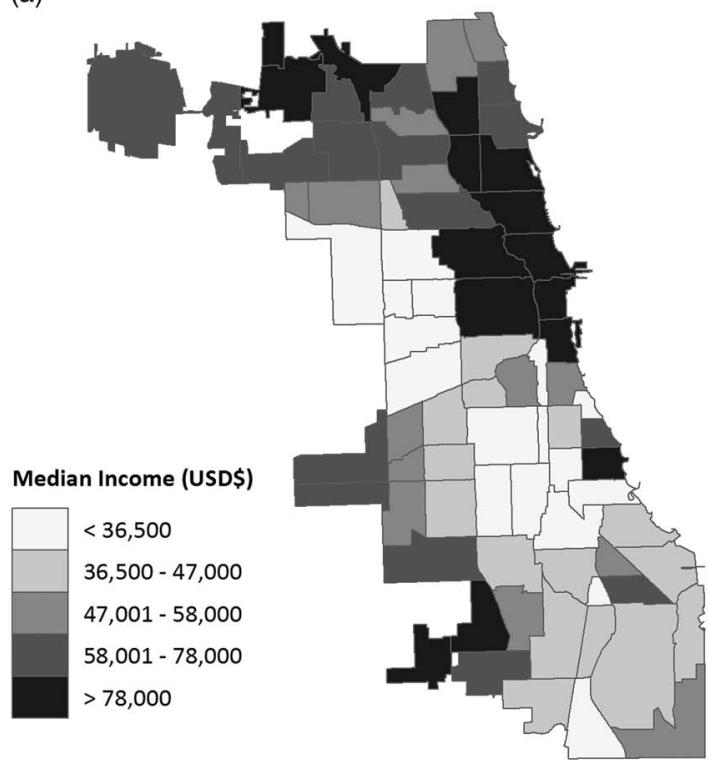

(c)

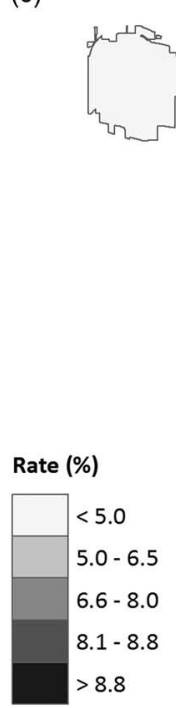

NAD 1983 UTM Zone 16N (b)

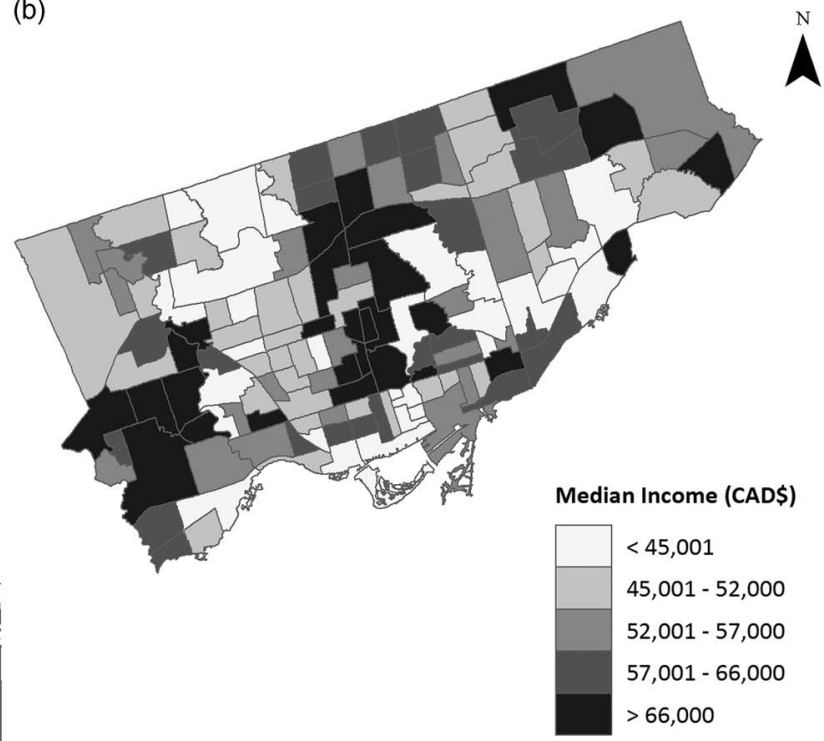

(d)

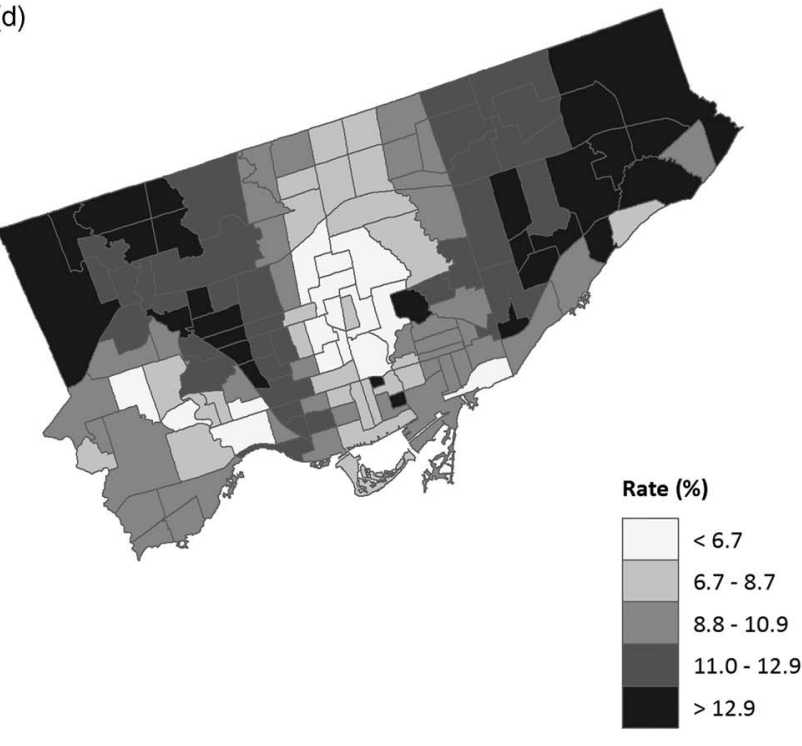

NAD 1983 UTM Zone 17N

Figure 1 Median income and diabetes prevalence rates for Toronto neighbourhoods and Chicago communities

The rates were derived from self-reported measures from the Illinois Behavioural Risk Factor Surveillance System; respondents reported whether they were diagnosed or told by a physician they have diabetes. Diabetes data is at the neighbourhood/community level, which was the unit of analysis. No individual-level data was used.

Primary Health Care Research \& Development 2017; 18: 291-299 
The socio-demographic data were acquired from Statistics Canada 2006 Census and the US Census Bureau ACS 2008-12 at the census tract level. The census tract data was aggregated to the appropriate neighbourhood/community units using relevant data conversion files; the aggregated census data represent the proportion of people with the characteristic, which is the central unit of analysis as all data used were acquired at the neighbourhood/community level. Contextual factors included indicators regarded as important determinants of health: unemployment, households below poverty, income earnings for economic families and individuals, private and public healthcare insurance, high school not completed, high school completed (diploma), postsecondary and graduate diplomas, degrees, place of birth (POB), and ethnicity. The majority of the variables were comparable with the exception of healthcare insurance and high school not completed, which were only applicable to Chicago or else not captured in the Canadian census.

\section{Methods}

The notion of geographic accessibility provides a useful framework to analyse the relative ease that individuals from one location reach other locations. The 2SFCA method was used to quantify how accessible neighbourhoods/communities were to physicians; it conceptualizes accessibility as a trade-off between spatial separation (distance to physician locations) and opportunity attractiveness (number of physicians in a given location) taking into consideration demand (neighbourhood/community populations) (see References for descriptions and implementations of the model). Potential spatial access refers to the availability of PCPs that can possibly be contacted by surrounding populations (Wang, 2006). PCPs were chosen as they are generally contacted first when healthrelated problems arise and are gatekeepers to specialized services (Harrington et al., 2012). The model required a physician catchment size, representing the maximum distance residents would travel to a PCP. Five kilometres was selected to be consistent with thresholds used in previous North American spatial access studies (Wang, 2007; Luo and Whippo, 2011; Hawthorne and Kwan, 2012). The resultant potential spatial access to PCPs scores were used in statistical analyses.
Bivariate correlation analysis was used to determine the contextual factors associated with diabetes prevalence. Pearson's correlation coefficients were generated between each contextual factor and diabetes prevalence rate at the neighbourhood/community level for both cities. Multivariate linear regression was used to quantify the amount of variance in diabetes prevalence that can be explained by the independent variables. The contextual factors that generated the most statistically significant coefficients were selected as the independent variables for multivariate linear regression through the stepwise method in SPSS (IBM version 22).

\section{Results}

The access scores revealed similar spatial patterns and had no statistically strong associations with diabetes prevalence for both cities. Figure 2 shows the resultant spatial access scores, where higher values denote higher access and vice versa. High access scores were concentrated within the downtown cores, while low access scores were located in the fringes of both cities. Nevertheless, potential spatial access to PCPs was negatively, weakly associated with diabetes prevalence for Toronto, and not significantly associated with diabetes prevalence in Chicago; see Table 1 for bivariate correlation results.

The social factors had stronger associations with diabetes prevalence. For both cities, unemployment, poverty and low education attainment were associated with diabetes prevalence. Neighbourhoods/communities characterized by high income and education (above bachelor's degree) were associated with low prevalence, while neighbourhoods/communities with low-to-middle income and lower education were associated with high prevalence. For Chicago, private insurance coverage was negatively associated with diabetes prevalence, while public health insurance had a positive association.

The associations between certain ethnicities and diabetes rates varied between the two cities. For Toronto, native born and North American ethnicity were negatively associated with diabetes rates, while foreign born, Asian POB and ethnicity had positive associations. For Chicago, native born and North American ethnicity were positively 
(a)

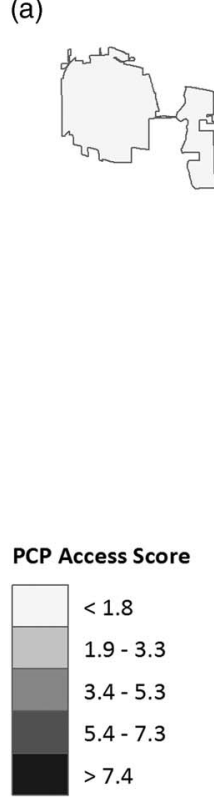

NAD 1983 UTM Zone 16N (b)

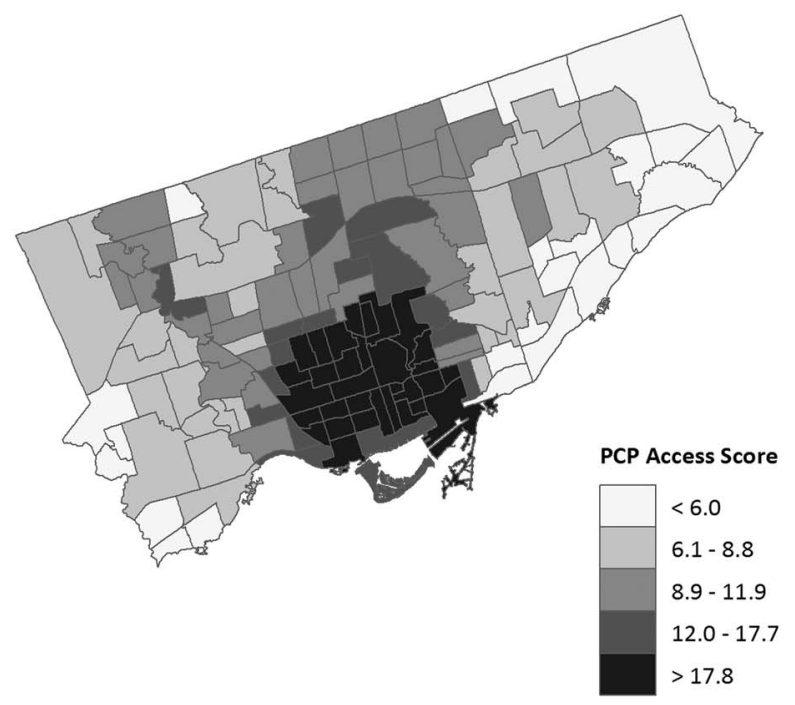

NAD 1983 UTM Zone 17N

Figure 2 Spatial potential access scores for Toronto neighbourhoods and Chicago communities

associated with diabetes prevalence, whereas foreign born, Asian POB and ethnicity had negative associations. For both cities, South American and African POB and ethnicity were positively related to diabetes, while European ethnicity (including subgroups) had a negative association.

Based on the Pearson's correlation results the following variables were chosen for the regression models: proportions of households below poverty, individuals completing high school, unemployment, South American POB and African ethnicity for Toronto, and proportions of households below poverty, individuals that did not complete high school, unemployment, African POB and African ethnicity for Chicago. Table 2 contains results of the multivariate linear regression models; Table 3 shows the results from the model that included public health insurance for Chicago. For Toronto, South American POB, households below poverty and high school diploma predicted $83.4 \%$ of the variance in diabetes prevalence $\left(R^{2}=0.834, \quad F(3,136)=2,17.364, \quad P<0.000\right)$. African ethnicity and households below poverty explained $47.3 \%$ of diabetes prevalence variance for Chicago $\left(R^{2}=0.473, F(2,74)=33.262, P<0.000\right)$.
The second model for Chicago identified public health insurance coverage as the only significant predictor, accounting for $50.2 \%$ of the variance $\left(R^{2}=0.502, F(1,75)=75.662, P<0.000\right)$.

\section{Discussion}

Despite a visual mismatch between the potential spatial access scores and diabetes prevalence across the neighbourhoods/communities (Figures 1 and 2), the statistical results indicate a weak (in Toronto) to no (in Chicago) association between diabetes prevalence and potential spatial access to PCPs. Interpretations need to consider the mixed findings in the literature about the role of distance and access to healthcare services; while poor spatial accessibility correlated with poor health outcomes in Syed et al. (2013), distance was not a significant factor for patients with chronic conditions in Arcury et al. (2005). Other considerations include data and 2SFCA model limitations. The diabetes prevalence data was measured differently between the cities (medical registry versus selfreport), which can bias results. The Modifiable

Primary Health Care Research \& Development 2017; 18: 291-299 
Table 1 Bivariate Pearson's correlation coefficients between diabetes prevalence and contextual social factors for Toronto neighbourhoods, 2006-07, and Chicago Communities, 2008-12

\begin{tabular}{|c|c|c|}
\hline \multirow[b]{2}{*}{ Contextual variables $^{a}$} & \multirow{2}{*}{$\frac{\text { City of Toronto }}{r(P \text {-value })}$} & \multirow{2}{*}{$\frac{\text { City of Chicago }}{r(P \text {-value })}$} \\
\hline & & \\
\hline Unemployment & $0.664 * *(<0.000)$ & $0.620 * *(<0.000)$ \\
\hline \multicolumn{3}{|l|}{ Individual income } \\
\hline Under $10000 \$$ & $0.559 * *(<0.000)$ & $0.603 * *(<0.000)$ \\
\hline $10000 \$-49999 \$$ & $0.606 * *(<0.000)$ & $0.492^{* *}(<0.000)$ \\
\hline Over $50000 \$$ & $-0.799 * *(<0.000)$ & $-0.633 * *(<0.000)$ \\
\hline \multicolumn{3}{|l|}{ Economic family income } \\
\hline Under $10000 \$$ & $0.240 * *(0.004)$ & $0.638 * *(<0.000)$ \\
\hline $10000 \$-49999 \$$ & $0.784 * *(<0.000)$ & $0.580 * *(<0.000)$ \\
\hline $50000 \$-99999 \$$ & $0.627 * *(<0.000)$ & $-0.224(0.050)$ \\
\hline Over $100000 \$$ & $-0.849 * *(<0.000)$ & $-0.612 * *(<0.000)$ \\
\hline Households below poverty & $0.622 * *(<0.000)$ & $0.643 * *(<0.000)$ \\
\hline \multicolumn{3}{|l|}{ Insurance coverage } \\
\hline With health insurance & N/A & $-0.223(0.051)$ \\
\hline With private health insurance & & $-0.610 *(<0.000)$ \\
\hline With public health insurance & & $0.709 * *(<0.000)$ \\
\hline With no insurance & & $0.205(0.074)$ \\
\hline \multicolumn{3}{|l|}{ Education level } \\
\hline No school & $0.757 * *(<0.000)$ & $-0.089(0.441)$ \\
\hline High school diploma ${ }^{b}$ & $0.819 * *(<0.000)$ & $0.442 * *(<0.000)$ \\
\hline High school, no diplomab & $\mathrm{N} / \mathrm{A}$ & $0.626 *(<0.000)$ \\
\hline College & $0.534 * *(<0.000)$ & $0.560 * *(<0.000)$ \\
\hline University/college certificate & $0.040(0.643)$ & $0.289 *(0.011)$ \\
\hline Bachelor's degree & $-0.842 * *(<0.000)$ & $-0.529 * *(<0.000)$ \\
\hline Master's degree & $-0.841 * *(<0.000)$ & $-0.516^{* *}(<0.000)$ \\
\hline Doctorate (PhD) & $-0.742 * *(<0.000)$ & $-0.469 * *(<0.000)$ \\
\hline Above bachelor's degree & $-0.818 * *(<0.000)$ & $-0.530 * *(<0.000)$ \\
\hline \multicolumn{3}{|l|}{ Place of birth } \\
\hline Native born & $-0.734 * *(<0.000)$ & $0.497 * *(<0.000)$ \\
\hline Foreign born & $0.637 * *(<0.000)$ & $-0.497 * *(<0.000)$ \\
\hline Europe & $-0.098(0.250)$ & $-0.486 * *(<0.000)$ \\
\hline Asia & $0.470 * *(<0.000)$ & $-0.423 * *(<0.000)$ \\
\hline Africa & $0.519 * *(<0.000)$ & $0.426^{* *}(<0.000)$ \\
\hline South America & $0.682 * *(<0.000)$ & $0.360 * *(0.001)$ \\
\hline North America & $-0.754 * *(<0.000)$ & $-0.410 * *(<0.000)$ \\
\hline Oceania & $-0.390 * *(<0.000)$ & $-0.328 * *(0.004)$ \\
\hline \multicolumn{3}{|l|}{ Ethnicity } \\
\hline Aboriginal & $0.107(208)$ & $-0.134(0.246)$ \\
\hline North American & $-0.511 * *(<0.000)$ & $0.405^{* *}(<0.000)$ \\
\hline Asian & $0.530 * *(<0.000)$ & $-0.443 * *(<0.000)$ \\
\hline South American & $0.766 * *(<0.000)$ & $0.357 * *(0.001)$ \\
\hline African & $0.654 * *(<0.000)$ & $0.569 *(<0.000)$ \\
\hline European & $-0.734 * *(<0.000)$ & $-0.569 *(<0.000)$ \\
\hline Western European & $-0.758 * *(<0.000)$ & $-0.397 *(<0.000)$ \\
\hline Northern European & $-0.718 * *(<0.000)$ & $-0.439 * *(<0.000)$ \\
\hline Eastern European & $-0.623 * *(<0.000)$ & $-0.359 *(0.001)$ \\
\hline Southern European & $0.310 * *(<0.000)$ & $-0.413^{*} *(<0.000)$ \\
\hline \multicolumn{3}{|l|}{ Potential spatial access scores to PCPs } \\
\hline Within $5 \mathrm{~km}$ catchment & $-0.373 * *(<0.000)$ & $-0.139(0.229)$ \\
\hline
\end{tabular}

a The variables listed represent proportions of individuals within the neighbourhood/community of the respective variable with the exception of the variable on potential spatial access scores to PCPs.

${ }^{\mathrm{b}}$ Refers to the proportion of individuals who (a) attended high school, but did not complete (High School, no Diploma) and (b) attended and completed high school (High School, Diploma).

*Two-tailed significance at the 0.05 level.

**Two-tailed significance at the 0.01 level. 
Table 2 Multivariate linear regression results for diabetes prevalence for Toronto neighbourhoods, 2006-07, and Chicago Communities, 2008-12

\begin{tabular}{|c|c|c|c|c|c|c|c|}
\hline \multicolumn{4}{|l|}{ City of Toronto } & \multicolumn{4}{|l|}{ City of Chicago } \\
\hline Independent variables & $\beta$ & SE & $P$-value & Independent variables & $\beta$ & SE & $P$-value \\
\hline Households below poverty & 0.081 & 0.017 & $<0.000$ & Households below poverty & 0.874 & 0.190 & $<0.000$ \\
\hline High school diploma & 0.344 & 0.034 & $<0.000$ & High school, no diploma & 0.323 & 0.010 & 0.010 \\
\hline Unemployment & 0.154 & 0.085 & 0.073 & Unemployment & 0.186 & 1.304 & 0.196 \\
\hline South American POB & 0.374 & 0.055 & $<0.000$ & African POB & 0.018 & 0.129 & 0.897 \\
\hline African ancestry & -0.091 & 0.055 & 0.102 & African ancestry & 0.346 & 0.119 & 0.005 \\
\hline$R^{2}$ & & $0.834^{* *}$ & & & & $0.473^{* *}$ & \\
\hline
\end{tabular}

$\mathrm{POB}=$ place of birth

**Two-tailed significance at the 0.01 level.

Table 3 Multivariate linear regression results with the inclusion of public health insurance for Chicago communities, 2008-12

\begin{tabular}{lllr}
\hline Independent variables & $\beta$ & $\mathrm{SE}$ & $P$-value \\
\hline Households below poverty & 0.168 & 1.132 & 0.261 \\
High school diploma & 0.001 & 0.008 & 0.993 \\
Unemployment & 0.083 & 0.551 & 0.583 \\
African POB & 0.167 & 1.915 & 0.059 \\
African ethnicity & 0.180 & 1.677 & 0.098 \\
Public health insurance & 1.224 & 0.141 & $<0.000$ \\
$R^{2}$ & & $0.503^{* *}$ & \\
\hline
\end{tabular}

$\mathrm{POB}=$ place of birth.

Areal Unit Problem is present due to the spatial units used (neighbourhood/community); it is possible that results will differ using data at smaller spatial scales. As discussed previously, the Chicago physician data set excluded about 800 PCPs as the publicly available data only includes 1132 . This introduces an analytical bias. The model also did not account for populations and PCPs located outside of the study areas. The $5 \mathrm{~km}$ threshold may not reflect the actual distance the populations would travel to PCPs, and is a dichotomous measure assuming that all individuals living within this distance have equal access (Wang, 2006). As this was an exploratory study, a simplified model was used instead of advanced models that consider transport mode and travel time which impact healthcare resource utilization (Wang, 2006; Toivakka et al., 2015). Nevertheless, the access scores identified neighbourhoods/communities with relatively low potential access to PCPs.

The results indicate that various contextual factors were associated, or predicted, the areal variance in diabetes prevalence for both cities.
Bivariate correlation revealed an income and education gradient previously acknowledged as significant at the individual level (Haydon et al., 2006; Creatore et al., 2010; Grigsby-Toussaint et al., 2010). The opposing associations between native- and foreign-born populations with diabetes prevalence between the cities may be explained by considering the healthy immigrant effect; immigrants typically have better health status upon arrival, which gradually deteriorates as they live in their host country (Vissandjee et al., 2004). The negative association found for Chicago may reflect the first phase, while the positive association for Toronto may reflect the later phase due to the variables; the Canadian foreign-born population attribute included all individuals granted landed immigrant status (Statistics Canada, 2011). Consequently, the findings for Toronto may be obscured as half of the population was born elsewhere in 2006 (City of Toronto, 2014).

The associations between ethnic groups and diabetes rates follow immigration trends for both cities. Results identified long-standing immigrant populations, specifically Southern Europeans in Toronto, and African, South and Native Americans in Chicago, through positive associations with diabetes. Negative associations were found for more recent immigrant groups for Chicago: South Americans, Eastern Europeans and Asians (Illinois Coalition for Immigration and Refuge Rights, 2010). As Toronto had more immigrants from Asia, Middle East and Latin America since 1980, the results may indicate that length of residency increases propensity for developing diabetes (Toronto Public Health, 2007). These associations also reflect past North American study findings which found that South 
Asian, African and Latin American immigrant populations have higher risks for diabetes (Vissandjee et al., 2004; Haydon et al., 2006; Creatore et al., 2010). The 'Westernized' diet and lifestyle were identified as reasons for differences; other studies suggested that recent immigrants tend to have lower-socio-economic status and difficulties in procuring employment with benefits, impacting their healthcare service use (Vissandjee et al., 2004; Dinca-Panaitescu et al., 2011; Jack et al., 2012). Consequently, these known links between ethnicity and socio-economic may also be affecting results, as statistical analyses identified several positive associations for certain ethnic groups and variables related to socio-economic status with diabetes prevalence; however, this would need to be further explored at the individual level.

For Chicago, public health insurance was a significant explanatory factor. Since public healthcare coverage is mostly granted to seniors and individuals that lack financial resources, or have disability benefits or certain health conditions (Klees et al., 2011), public healthcare coverage can be a proxy for socio-economic status. Thus, the results may be identifying the most vulnerable communities as those with higher proportions of seniors, who have a greater propensity for diabetes, and individuals that have public health insurance coverage.

\section{Conclusion}

This study demonstrated that statistical analyses can identify contextual factors that were associated with, or predicted, diabetes prevalence for two North American cities differing in healthcare systems and population socio-economic composition at the neighbourhood/community level. The results should be interpreted with caution as this study investigated neighbourhood-level contextual factors (related to spaces), not compositional factors (related to individuals). Accordingly, smaller areal units can be utilized with health data at the same level to determine whether other contextual factors are associated with, and can predict, variances in health outcomes. Although additional research is required to verify the findings, these methods can potentially help identify disadvantaged groups within the neighbourhoods/

Primary Health Care Research \& Development 2017; 18: 291-299 communities requiring more health-related resources, structural improvements, or health intervention programmes. Relevant health resource allocation and policy changes can be made to directly impact the most vulnerable neighbourhoods/communities to improve their overall health.

\section{Acknowledgements}

The authors would like to thank Rajiv Lalla, Alyssa Wynnyk and Victoria Polsinelli for guidance, proofreading and editing.

\section{Financial Support}

This research received no specific grant from any funding agency, commercial or not-for-profit sectors.

\section{Conflicts of Interest}

None.

\section{Ethnical Standards}

An ethics approval was not required for this research as all health and demographic data used in the statistical analyses were publicly available data sets.

\section{References}

Arcury, T.A., Gesler, W.M., Preisser, J.S., Sherman, J., Spencer, J. and Perin, J. 2005: The effects of geography and spatial behavior on health care utilization among the residents of a rural region. Health Services Research 40, 135-56.

American Academy of Family Physicians 2014: Primary care physician mapper. Retrieved 14 April 2014 from http://www. graham-center.org/online/graham/home/tools-resources/npi. html.

Centers for Disease Control and Prevention 2014. National diabetes statistics report: estimates of diabetes and its burden in the United States. Atlanta, GA: US Department of Health and Human Services.

Centers for Medicare and Medicaid Services 2014: Official physician compare data. Retrieved 14 April 2014 from https://data.medicare.gov/data/physician-compare.

City of Toronto 2014: Toronto facts: diversity. Retrieved 18 June 2014 from http://www1.toronto.ca/ wps/portal/content only?vgnextoid=dbe867b42d853410VgnVCM10000071d6 0f89RCRD\&v gnextchanne $1=57 \mathrm{a} 12 \mathrm{cc} 817453410 \mathrm{VgnVCM}$ 10000071d60f89RCRD. 
Creatore, M.I., Moineddin, R., Booth, G., Manuel, D.H., DesMeules, M., McDermott, S. and Glazier, R.H. 2010: Age- and sex-related prevalence of diabetes mellitus among immigrants to Ontario, Canada. International Journal of Preventative Medicine 3, 8-16.

Diez Roux, A.V. and Mair, C. 2010: Neighbourhoods and health. Annals of the New York Academy of Sciences 1186, 125-45.

Dinca-Panaitescu, S., Dinca-Panaitescu, M., Bryant, T., Daiski, I., Pilkington, B. and Raphael, D. 2011: Diabetes prevalence and income: results of the Canadian Community Health Survey. Health Policy 99, 116-23.

Forouhi, N.G. and Wareham, N.J. 2010: Epidemiology of diabetes. Medicine 38, 602-7.

Grigsby-Toussaint, D., Lipton, R., Chavez, N., Handler, A., Johnson, T.P. and Kubo, J. 2010: Neighbourhood socioeconomic change and diabetes risk. Diabetes Care 33, 1065-69.

Harrington, D.W., Wilson, K., Bell, S., Muhajarine, N. and Ruthart, J. 2012: Realizing neighbourhood potential? The role of the availability of health care services on contact with a primary care physician. Health \& Place 18, 814-23.

Hawthorne, T.L. and Kwan, M. 2012: Using GIS and perceived distance to understand the unequal geographies of healthcare in lower-income urban neighbourhoods. The Geographic Journal 178, 18-30.

Haydon, E., Roerecke, M., Giesbrecht, N., Rehm, J. and Kobus-Matthews, M. 2006. Chronic disease in Ontario and Canada: determinants, risk factors and prevention priorities. Toronto, ON: Ontario Public Health Association.

Illinois Coalition for Immigration and Refuge Rights. 2010: US and Illinois immigrants by the numbers. Retrieved 18 June 2014 from http://icirr.org/sites/default/files/fact \%20sheetdemography\%202011.pdf.

Jack, L., Jack, N.K. and Hayes, S.C. 2012: Social determinants of health in minority populations: a call for multidisciplinary approaches to eliminate diabetes-related health disparities. Diabetes Spectrum 25, 9-13.

Klees, B.S., Wolfe, C.J. and Curtis, C.A. 2011: Brief summaries of medicare and medicaid. Retrieved 14 April 2014 from https://www.cms.gov/Research-Statistics-Data-and-Systems/ Statistics-Trends-and-Reports/MedicareProgramRatesStats/ downloads/MedicareMedicaidSummaries2011.pdf.
Luo, W. and Whippo, T. 2011: Variable catchment sizes for the two-step floating catchment area (2SFCA) method. Health \& Place 18, 789-95.

Public Health Agency of Canada 2011. Diabetes in Canada: facts and figures from a public health perspective. Ottawa: Public Health Agency of Canada.

Smith, D.G. 2008: The uninsured in the US healthcare system. Journal of Healthcare Management 53, 79-81.

Statistics Canada 2011: Place of birth, generation status, citizenship and immigration reference guide, 2006 Census. Retrieved 18 June 2014 from https://www12.statcan.gc.ca/ census-recensement/2006/ref/rp-guides/immigration-eng.cfm.

Syed, S.T., Gerber, B.S. and Sharp, L.K. 2013: Traveling towards disease: transportation barriers to health care access. Journal of Community Health 38, 976-93.

Toronto Community Health Profiles Partnership 2014: Data: adult health and disease datasets. Retrieved 15 January 2014 from http://www.torontohealthprofiles.ca/a_data Tables.php?varTab=HPDtbl.

Toronto Public Health 2007: Release of the 2006 Census on language, immigration, citizenship, mobility/migration. Retrieved 18 June 2014 from http://www1.toronto.ca/city_ of_toronto/social_development_finance_administration/files/ pdf/2006_lang_imm_citizenship_mobility_backgrounder.pdf.

Toivakka, M., Laatikainen, T., Kumpula, T. and Tykkyläinen, M. 2015: Do the classification of areas and distance matter to the assessment results of achieving the treatment targets among type 2 diabetes patients? International Journal of Health Geographics 14, 27. doi:10.1186/s12942-015-0020-x.

Vissandjee, B., Desmeules, M., Cao, Z., Abdool, S. and Kazanjian, A. 2004: Integrating ethnicity and migration as determinants of Canadian women's health. BMC Women's Health 4, 1-11.

Wang, F. 2006. Quantitative methods and applications in GIS. Boca Raton, FL: Taylor \& Francis Group.

Wang, L. 2007: Immigration, ethnicity, and accessibility to culturally diverse family physicians. Health \& Place 13, 656-71.

Wang, L. and Hu, W. 2013: Immigrant health, place effect and regional disparities in Canada. Social Science \& Medicine 98, 8-17. 